Sri Lanka J. Aquat. Sci. 20 (2) (2015): 1-8

\title{
Impact of introduction of culture-based fisheries on fish production and socio-economic conditions of fishers in Ampara wewa, a medium perennial reservoir
}

\author{
K.B. Chandrani Pushpalatha*, Jayantha Chandrasoma and W.M.J. Rohitha \\ Fernando
}

National Aquaculture Development Authority of Sri Lanka, No. 41/1, New Parliament Road, Pelawatte, Battaramulla, Sri Lanka

*Corresponding author (pushpakbc@yahoo.com)

\begin{abstract}
Introduction of culture-based fisheries $(\mathrm{CBF})$ in minor perennial reservoirs is a recent development in Sri Lanka. CBF was introduced to Ampara wewa, (240 ha at FSL), a medium-sized perennial reservoir situated in the Eastern Province of Sri Lanka. Main activities involved in introduction of CBF were reorganization and strengthening of community-based fishers' organization (CBO), training of $\mathrm{CBO}$ members, preparation of a development plan, stocking, introduction of fishery management measures and harvesting. Main species used in stocking was Nile tilapia. Other species used were catla, rohu and freshwater prawn (FWP).

Introduction of $\mathrm{CBF}$ resulted in an increase of total average annual fish production of the reservoir from 5.6 to 118.1 tonnes. Main contributors to fish production after establishment of CBF were Nile tilapia (82.2\%), catla (12.7\%) and rohu (2.4\%). Biomass gain of fish per fingerling of Nile tilapia, catla, rohu and freshwater prawn were $0.23,0.45,0.14$ and 0.0048 respectively. Monetary gains for stocking a fingerling of tilapia, catla and rohu were Rs. 27.11, 38.59 and 10.87 respectively. Stocking of FWP had a negative monetary gain.

With the establishment of CBF, number of full time fishers engaged in fishing increased from 13 to 33 . In addition there were 22 part-time fishers. Similarly number of fish traders engaged in selling fish from Ampara wewa increased from 3 to 13. Average monthly income of a fisher was Rs. 40,360 after the establishment of $\mathrm{CBF}$, which was a five-fold increase from pre-CBF period. Higher income has resulted in enhanced standard of living among fishers. Thirty percent of the fishers built new houses, and 70\% improved/expanded existing houses. Sixty six percent of full time fishers purchased motor bicycles, whereas 39.3\% purchased threewheelers utilizing enhanced income from CBF. All 33 full-time fishers had saving accounts and $66 \%$ of the full-time fishers saved money in banks in the name of their dependents.
\end{abstract}

Keywords: community based organization, perennial reservoir, biomass gain, Nile tilapia, Indian major carps. 
K.B.C. Pushpalatha et al./Sri Lanka J. Aquat. Sci. 20 (2) (2015): 1-8

\section{Introduction}

In Sri Lanka, reservoir construction has been an integral part of ancient human civilization, with some major reservoirs over 2000 years old. The cumulative total extent is about 200,000 ha (Jayasinghe and Amarasinghe 2015). On average, they range from a few ha to 4,000 ha and depending on their hydrological regimes, they are broadly categorized into perennial and seasonal reservoirs, and are secondarily used for inland fisheries.

The Government of Sri Lanka has recognized culture-based fisheries (CBF) as an effective means of increasing food supplies in rural areas at affordable prices. CBF provide employment opportunities and additional income to rural communities and thereby contribute towards poverty alleviation. CBF yields are based predominantly on the recapture of stocked fish. Stocking is known to be effective in increasing yields where natural recruitment is lower than the habitat carrying capacity (Cowx 1994). CBF are less resource-intensive and require fewer technical skills at farmer level, allowing communities with relatively limited experience to engage in extensive fish culture.

CBF in seasonal reservoirs of Sri Lanka was initiated in early 1980s and its development was well documented (Thayaparan 1982; Chakrabarty and Samaranayake 1983; Chandrasoma 1986; Chandrasoma and Kumarasiri 1986; De Silva et al. 2006). Ministry of Fisheries and Aquatic Resource Development of Sri Lanka has recently introduced a programme to introduce CBF into perennial reservoirs. The perennial reservoirs of the country are broadly divided into three categories based on the extent; minor ( $<200 \mathrm{ha})$, medium (200-800 ha) and major (>800 ha). Some seasonal reservoirs have also become perennial in nature, due to the supply of water through new irrigation schemes. Pushpalatha and Chandrasoma (2009) demonstrated the potential of minor perennial reservoirs for improving fish yields through $\mathrm{CBF}$, which included planned stocking of fish fingerlings and proper management of fisheries.

This paper evaluates the impact of introducing CBF in Ampara wewa, a medium perennial reservoir situated in the Eastern part of Sri Lanka, in terms of increasing fish yield, income of fishers and their standard of living.

\section{Material and Methods}

\section{Ampara wewa}

Ampara wewa is a minor perennial tank ( 240 ha at FSL) situated in the Ampara district. In the Eastern Province of Sri Lanka. Although commercial fishing involving 13 fishers, based on self-breeding tilapia and indigenous species existed, fish production had been very low. There had been no proper stocking and no proper management of the fishery.

Although there had been a community-based organization (CBO) in the form of a fisheries society in existence at Ampara wewa the organization status of the CBO was weak. Since 1980s, the fisheries authorities made membership of a fisher $\mathrm{CBO}$ as a pre-requisite for the provision of subsidies related to fishing canoes, 
K.B.C. Pushpalatha et al./Sri Lanka J. Aquat. Sci. 20 (2) (2015): 1-8

fishing gear and housing for fishers. As such, inland fishers tended to organize themselves into CBOs for the sole purpose of enjoying benefits of state-sponsored subsidy schemes. This top-down approach was not effective for the management of reservoir fishery as the fishers' interest to organize into societies. The CBO of the Ampara wewa too was not an exception and the members did not make significant contribution to sustain $\mathrm{CBO}$.

\section{Introduction of culture-based fisheries}

Awareness of $\mathrm{CBF}$ was created among village communities, members of respective farmer organizations and fishers. The Participatory Rural Appraisal (PRA) approach was used as a tool to motivate relevant communities including fishers living around the reservoir, to analyze their own conditions, suggest solutions and organize themselves to implement CBF.

As reliable data on fish production and species composition was not available in the log-book records of CBO, fish production in 2004 and 2005 was estimated through sampling to indicate pre-CBF status in the fishery. Other activities undertaken to introduce CBF included, reorganization and strengthening of fishers' $\mathrm{CBO}$, preparation of a CBF development plan which slpelled out stocking plan, harvesting, implementation of fisheries management measures and catch data recording system.

\section{Fishers' community-based organization}

As a pre-requisite to undertake culture-based fisheries, fishers' $\mathrm{CBO}$ was reorganized, with the participation of fishers and would be fishers. Members of the CBO were given training in basic aspects of CBF. Further, they were provided with training in $\mathrm{CBO}$ management, leadership, simple accounting, book keeping, and record keeping etc.

\section{Planning of activities}

With the assistance of the Fisheries Extension Officer of the area CBO members prepared a plan for development of CBF in their reservoir. This development plan consisted of a stocking plan, management plan and a business plan. Fish species to be stocked, stocking densities to be adopted, time for stocking, source of fish seed etc., were included in the stocking plan. For taking decisions on the species to be stocked, CBO gave due consideration to consumer preference and availability of fish seed. The stocking plan was revised in subsequent years, depending on the stocking outcome. The management plan included management measures to be adopted. Business plan indicated anticipated fish production, overall income through $\mathrm{CBF}$, income for $\mathrm{CBO}$, income for fishers etc. through implementation of stocking and management plans. 
K.B.C. Pushpalatha et al./Sri Lanka J. Aquat. Sci. 20 (2) (2015): 1-8

\section{Reservoir stocking}

Since 2006, stocking of hatchery produced Nile tilapia, Oreochromis niloticus, catla, Catla catla, rohu, Labeo rohita and freshwater prawn, Macrobrachium rosenbergii has been a regular activity in the reservoir. Stocking numbers were based on stocking plans prepared by $\mathrm{CBO}$ members and the availability of fingerlings. Total number of fish fingerlings stocked during 5-year period was 2.28 million, which accounted for $77.5 \%, 5.8 \%, 3.5 \%$ and $13.2 \%$ of fingerlings and/or postlarvae of Nile tilapia, catla, rohu and freshwater prawn respectively. Average stocking of Nile tilapia was $1472 \mathrm{ha}^{-1} \mathrm{yr}^{-1}$. Average total length of fish fingerlings at stocking was 5-6 cm for carp species and 6-8 $\mathrm{cm}$ for Nile tilapia. Freshwater prawn post larvae (PL) of day 45 was used for stocking.

\section{Fisheries management measures}

Fisher CBO was actively involved in implementation of fisheries management measures. Regulations of the Fisheries and Aquatic Resources Act (of 1996 were strictly adhered to. Although the minimum mesh size of gill nets was $85 \mathrm{~mm}, \mathrm{CBO}$ members collectively agreed and used gill nets of mesh size $115 \mathrm{~mm}$ and above. CBO members agreed on a fixed time period for carrying out fishing operations $(5.00 \mathrm{pm}$ to $7.30 \mathrm{am})$. Further, surveillance of the reservoir to observe any unauthorized fishers was carried out routinely by $\mathrm{CBO}$ members.

\section{Harvesting}

Harvesting of fish is a year round activity in the reservoir. Non mechanized fiberglass outrigger canoes are used for fishing. Fishing gear is gill net with stretched mesh sizes ranging from $115 \mathrm{~mm}$ to $200 \mathrm{~mm}$. In general, each canoe is operated by two fishers who place their nets in the evening and haul them in the next morning.

\section{Catch data collection}

Species-wise fish catch data was recorded by the CBO on the daily basis in a computerized database. This computer-assisted data recording system in a rural reservoir has been an innovative approach for active involvement of a CBO for reliable data collection.

\section{Impact of CBF on socio-economic conditions of fishers}

Information pertaining to the socio economic conditions of the fishers was collected in 2010 through administering a questionnaire. Information in respect of income from CBF, savings, acquisition of capital assets etc. was collected. 
K.B.C. Pushpalatha et al./Sri Lanka J. Aquat. Sci. 20 (2) (2015): 1-8

\section{Fish production}

\section{Results}

Fish production of the reservoir increased significantly, after the introduction of CBF. Average annual fish production increased from 7.5 tonnes in 2004-2006 to 118.1 tonnes in 2007-2010, with an increase in fish yield from 31.3 to $492.1 \mathrm{~kg} \mathrm{ha}^{-1}$ $\mathrm{yr}^{-1}$.

\section{Species composition}

Oreochromis mossambicus was the most abundant fish species (77\%) prior to the introduction of CBF, with indigenous Channa striata, Clarias brachysoma and exotic Trichogaster pectoralis contributing towards the rest. By 2009, O. niloticus (81.7\%) became the main contributor to the fish catches. Other important contributions came from catla (12.5\%), rohu (2.3\%) and other indigenous fish species (2.5\%). freshwater prawn was only $0.3 \%$.

\section{Monetary gain of stocking}

Average biomass gains ranged from $0.005 \mathrm{~kg}$ per PL of freshwater prawn to $0.45 \mathrm{~kg}$ per catla fingerling (Table 1). Market value of harvested fish also ranged in the same magnitude with Rs. 1.44 per PL of freshwater prawn to Rs. 40.5 per fingerling of catla (Table 1). Consequently, monetary gains of stocking per fingerling were Rs. 26.6, 38.5 and 10.6 for Nile tilapia, catla and rohu respectively. However, monetary gain of stocking freshwater prawn was negative (-0.56).

Table 1. Details on biomass gain per fingerling/PL stocked and monetary gains of stocking of Nile tilapia, catla, rohu and freshwater prawn (FWP).

\begin{tabular}{llll}
\hline Fish Species & $\begin{array}{l}\text { Weight gain of } \\
\text { fish per } \\
\text { fingerling/PL } \\
\text { stocked (kg) }\end{array}$ & $\begin{array}{l}\text { Market value of fish } \\
\text { per fingerling/PL } \\
\text { stocked (Rs.) } \dagger\end{array}$ & $\begin{array}{l}\text { Monetary gain of } \\
\text { stocking (market } \\
\text { value of fish } \\
\text { harvested/ } \\
\text { fingerling cost) } \ddagger\end{array}$ \\
\hline Nile Tilapia & 0.22 & 28.6 & 26.6 \\
Catla & 0.45 & 40.5 & 38.5 \\
Rohu & 0.14 & 12.6 & 10.6 \\
FWP & 0.005 & 1.44 & $(-0.56)$
\end{tabular}

$\uparrow$ Selling price existed in 2010 was SL Rs. 130 per kg for Tilapia, Rs. 90 per kg of rohu and catla and Rs. 300 per $\mathrm{kg}$ for freshwater prawn; $\$$ Cost of a fingerling/PL $=$ SL Rs. 2 (In 2010, US \$ 1 = SL Rs. 108). 
K.B.C. Pushpalatha et al./Sri Lanka J. Aquat. Sci. 20 (2) (2015): 1-8

Socio-economic conditions of fishers

Details of socio-economic conditions of fishers of Ampara wewa are summarized in Table 2. Introduction of CBF supported livelihoods for 67 villagers, which was a four-fold increase from that of pre-CBF period. There had been a significant increase $(355 \%)$ in the average monthly income of full-time fishers. Almost all the full-time fishers have utilized their enhanced earnings from CBF to improve housing. Moreover, $60.6 \%$ of full-time fishers have purchased motor bicycles and $39.3 \%$ purchased three-wheelers. All 33 full time fishers had savings accounts in state banks while 22 of them had opened savings accounts in the names of their dependents.

Table 2. Details of socio-economic conditions of fishers of Ampara wewa.

\begin{tabular}{|c|c|c|}
\hline & $\begin{array}{c}\text { Year } \\
2004-2005\end{array}$ & $\begin{array}{l}\text { Year } \\
2010\end{array}$ \\
\hline $\begin{array}{l}\text { (1) Provision of livelihood } \\
\text { - Total No. of full-time fishers } \\
\text { - No. of part-time fishers } \\
\text { - No. of fish traders }\end{array}$ & $\begin{array}{c}13 \\
- \\
3\end{array}$ & $\begin{array}{l}33 \\
21 \\
13\end{array}$ \\
\hline $\begin{array}{l}\text { (2) Average monthly income of a full- } \\
\text { time fisher }\end{array}$ & Rs.8,862 & Rs.40,366 \\
\hline $\begin{array}{l}\text { (3) Financial status of the fisher CBO } \\
\text { (deposits) }\end{array}$ & Rs.135,000 & Rs.2,824,756 \\
\hline $\begin{array}{l}\text { (4) Houses } \\
\text { - New houses built } \\
\text { - Existing house renovated } \\
\text { - Existing houses } \\
\quad \text { renovated/expanded }\end{array}$ & $\begin{array}{l}- \\
- \\
-\end{array}$ & $\begin{array}{c}10 \\
19 \\
4\end{array}$ \\
\hline $\begin{array}{l}\text { (5) Acquisition of capital Assets by full } \\
\text { time fishers } \\
\text { - Motor bicycles } \\
\text { - Three wheelers } \\
\text { - Cars }\end{array}$ & $\begin{array}{l}5 \\
1 \\
0\end{array}$ & $\begin{array}{c}18 \\
13 \\
1\end{array}$ \\
\hline $\begin{array}{l}\text { (6) Savings of full time fisher } \\
\text { - Number of savings accounts of } \\
\text { full-time fishers } \\
\text { - No. of fishers, who opened } \\
\text { savings accounts on behalf of } \\
\text { wife/children }\end{array}$ & 2 & $\begin{array}{l}33 \\
22\end{array}$ \\
\hline
\end{tabular}


K.B.C. Pushpalatha et al./Sri Lanka J. Aquat. Sci. 20 (2) (2015): 1-8

\section{Discussion}

Development of CBF in minor perennial tanks is a recent development in Sri Lanka. Stocking coupled with proper management of fisheries have resulted in significant increase in fish production. Pushpalatha and Chandrasoma (2009) reported production increase of $42.8 \%$ to $1344 \%$ after the introduction of CBF in 15 minor perennial reservoirs. Average annual fish yield in Ampara wewa during 2007-2010 period was $492.1 \mathrm{~kg} \mathrm{ha}^{-1}$. Pushpalatha and Chandrasoma (2009) reported average annual fish yield of $208.1 \mathrm{~kg} \mathrm{ha}^{-1}$ (ranging from 81.3 to $533.0 \mathrm{~kg} \mathrm{ha}^{-1}$ ) in 15 minor perennial reservoirs after introducing CBF. Annual fish yield in seasonal reservoirs, where CBF was introduced ranged from 220 to $2300 \mathrm{~kg} \mathrm{ha}^{-1}$ with the average of 892 $\mathrm{kg} \mathrm{ha}^{-1}$ (Chandrasoma and Kumarasiri 1986). Nile Tilapia fetches a higher price in Ampara area, compared to carps. Hence there is a tendency for fishers to adopt higher stocking densities of Nile Tilapia. Stocking amounting to $77.5 \%$ resulted in high dominance of Nile Tilapia in catches (81.7\%), while 5.8\% and 3.5\% of total stocking resulted in contribution of $12.5 \%$ and $2.5 \%$ of catla and rohu respectively to the fish catch. In minor perennial reservoirs, three exotic carps, namely catla, rohu and common carp together contributed $48.4 \%$ of the total fish production, while average contribution of Nile tilapia was $47.4 \%$ (Pushpalatha and Chandrasoma 2009).

Monetary gain of stocking of Nile tilapia, catla and rohu were attractive. Further, from the findings of present study and those reported by Pushpalatha and Chandrasoma (2009), it is evident that from the point of view of consumer preference and colonization success, Nile tilapia is a good candidate for CBF in minor and medium perennial reservoirs of Sri Lanka. Although Pushpalatha and Chandrasoma (2009) reported that stocking of FWP in minor perennial reservoirs is attractive, it was not so in Ampara wewa. This indicates that stocking of FWP for CBF development should be considered through a holistic approach, where high survival rates of stocked FWP can be achieved in the prevailing conditions such as predatory pressure.

Introduction of $\mathrm{CBF}$ in Ampara wewa has resulted in providing enhanced livelihoods, significantly higher income for fishers/traders and increased standards of living of fisher communities. Active fishers' $\mathrm{CBO}$ was the key to success in $\mathrm{CBF}$ in Ampara wewa. A good cooperation existed between the $\mathrm{CBO}$ and the fisheries extension officer in the area. It is of authors' view that dedicated facilitation is needed for achieving this kind of a success through active participation of $\mathrm{CBO}$, membersas mentioned by Amarasinghe and De Silva (1999), in CBF management. $\mathrm{CBO}$ member not only refrained from using illegal fishing gear but also prevented any unauthorized fishing in the reservoir, through implementation of surveillance. Funds required for stocking were generated by the $\mathrm{CBO}$ through a levy charged for every $\mathrm{kg}$ of fish landed. CBO's involvement in collection and maintenance of stocking and catch data has resulted in availability of very accurate data, which is useful for the $\mathrm{CBO}$ as well as for fisheries authorities for planning purposes. 
K.B.C. Pushpalatha et al./Sri Lanka J. Aquat. Sci. 20 (2) (2015): 1-8

\section{References}

Amarasinghe, U.S. \& S.S. De Silva 1999. Sri Lankan reservoir fishery: a case for introduction of a co-management strategy. Fisheries Management and Ecology 6: 387-399.

Chakrabarty, R. D. \& R.A.D.B. Samaranayake 1982. Fish culture in seasonal tanks in Sri Lanka. Journal of Inland fisheries, Sri Lanka 2: 125-140.

Chandrasoma, J. 1986. Primary productivity and fish yield in ten seasonal tanks in Sri Lanka. Journal of Inland fisheries, Sri Lanka 3: 56-62.

Chandrasoma, J. \& W.S.A.A.L. Kumarasiri 1986. Observations on polyculture of fish in seasonal tanks in Ratnapura and Moneragala districts in Sri Lanka. Journal of Inland fisheries, Sri Lanka 3: 49-55.

Cowx, I.G. 1994. Stocking strategies. Fishereis Management and Ecology 1: 15-30.

De Silva, S.S., U.S. Amarasinghe \& T.T.T. Nguyen 2006. Better practice approaches for culture based fisheries development in Asia. ACIAR Monograph No. 120, pp 96.

Jayasinghe, J.M.P.K. \& U.S. Amarasinghe 2015. Inland Aquatic Resources. In: Natural Resources of Sri Lanka: Conditions, Trends and Prospects. National Science Foundation of Sri Lanka, Colombo. pp. 00-00 (in press).

Pushpalatha, K.B.C. \& J. Chandrasoma 2009. Culture-based fisheries in minor perennial reservoirs in Sri Lanka: Variability in production, stocked species and yield implications. Journal of Applied Icthyology 26: 98-103.

Thyayaparan, K. 1982. The role of seasonal tanks in the development of freshwater fisheries in Sri Lanka. Journal of Inland fisheries, Sri Lanka 1: 133-167. 